\section{Effects of Selective Versus Non- Selective COX-2 Inhibition on Experimental Periodontitis}

Marcella Goetz Moro ${ }^{1}$, Marilia Dantas dos Santos Oliveira1, Leticia Rodrigues de Oliveira ${ }^{1}$, Simone Aparecida Teixeira² ${ }^{\mathbb{D}}$, Marcelo Nicolas Muscará $^{2} \mathbb{B}$, Luis Carlos Spolidorio ${ }^{3}$, Marinella Holzhausen ${ }^{1}$
'Department of Stomatology, Discipline of Periodontology, School of Dentistry, USP - Universidade de São Paulo, São Paulo, SP, Brazil ${ }^{2}$ Department of Pharmacology, Institute of Biomedical Sciences, USP - Universidade de São Paulo, São Paulo, SP, Brazil ${ }^{3}$ Department of Oral Pathology, Dental School of Araraquara, UNESP - Universidade Estadual Paulista, Araraquara, SP, Brazil

Correspondence: Marinella Holzhausen, Av. Prof. Lineu Prestes, 2227, 05508-000 São Paulo, SP, Brasil. Tel: +55-11-2648-8051. e-mail: marinella@usp.br
In the present study we compared the effects of the selective COX-2 inhibitor etoricoxib with those of the classical non-selective NSAID diclofenac on the inflammatory process and alveolar bone loss in an experimental model of periodontitis in rats. Ninety male Holtzman rats $(250 \mathrm{~g})$ were randomly sorted into four experimental groups: Sham+CMC and Ligature+CMC (control) groups which received $0.5 \%$ carboxymethylcellulose sodium (CMC) solution; Ligature+Diclofenac and Ligature+Etoricoxib groups which received Potassium Diclofenac and Etoricoxib, respectively, suspended in 0.5\% CMC (10 $\mathrm{mg} / \mathrm{kg} /$ day). At 7, 14 and 21 days after placing ligatures in the cervical region of both the lower right and left first molars, the animals were euthanized. At the end of each period, the mandibles were collected for radiographic examination of alveolar bone loss. In addition, alveolar bone and periodontal ligament tissue samples were collected for COX-2 expression analysis and gingival tissues were collected for measurement of $\mathrm{PGE}_{2}$ contents. Animals with ligature-induced periodontal disease showed significant increased cOX-2 gene expression at days 7, 14 and $21(\mathrm{p}<0.05)$ on alveolar bone and periodontal ligament. However, both treatments resulted in significantly reduced alveolar bone loss when compared to the untreated Ligature group $(p<0.05)$, with no statistical difference between Etoricoxib and Diclofenac Potassium groups. This study shows that both drugs were able to reduce alveolar bone loss after periodontal disease induction.
Key Words: periodontitis, cyclooxygenase inhibitors, rats.

\section{Introduction}

Periodontitis is a highly prevalent chronic inflammatory and multifactorial disease that affects approximately $46 \%$ of American individuals aged 30 years or older (1). The disease is triggered by a complex group of anaerobic Gram-negative bacteria that colonize and proliferate at subgingival area (2), which affect the protective and supporting structures leading to future tooth loss (3). Although the presence of biofilm and their products have been considered the main etiologic factor, the development and progression of periodontal disease is associated with the host immuno-inflammatory response (4).

In this process, the metabolism of arachidonic acid by cyclooxygenase (COX) isoenzymes, COX-1 and COX-2, leads to the synthesis of different eicosanoids, such as prostaglandins, prostacyclin and thromboxane $(5,6)$. COX2-derived prostaglandin E2 $\left(\mathrm{PGE}_{2}\right)$ is formed by activated macrophages and fibroblasts and plays a fundamental role in the alveolar bone destruction by modulating the inflammatory cascade in periodontitis $(4,7)$. $\mathrm{PGE}_{2}$ is present in the crevicular fluid and mediates vasodilation and increases the vascular permeability (8). Conversely, COX-1 isoform, is constitutively present in most cells and tissues and is responsible for the production of prostanoids involved in the maintenance of homeostasis, such as gastric mucosa protection and platelet aggregation. However, it has been shown that in addition to physiological functions, COX-1 is also involved in periodontal disease (9).

COX-2 expression is significantly increased during periodontal inflammation, and the use of drugs that inhibit this isoenzyme should block the production of $\mathrm{PGE}_{2}$ and might thus be considered for tissue damage prevention (7). With basis on their selectivity towards COX inhibition, non-steroidal anti-inflammatory drugs (NSAIDs) can be classified as non-selective (classical NSAIDs inhibit both COX-1 and COX-2 isoforms, such as diclofenac) or selective COX-2 inhibitors (or coxibs, such as etoricoxib) (10).

Potassium diclofenac (Cataflam ${ }^{\circledR}$ ) is mainly used for control of both acute and post-operative pain. In addition, it has been shown that during ligature-induced periodontitis in rats, diclofenac was also able to reduce the resulting leukocytosis, neutrophilia, lymphocytosis and alveolar bone loss (11). However, as it is the case with other classical NSAIDs, increased risk of gastrointestinal mucosa ulceration and bleeding is one of the most important side effects of diclofenac, which is due to the decreased production of 
locally protective COX-1-derived prostanoids, such as $\mathrm{PGE}_{2}$ and prostacyclin $\left(\mathrm{PGI}_{2}\right)$ (11). In this way, selective COX-2 inhibitors are devoid of these deleterious effects (12). Of these, etoricoxib (available in some European countries, Latin-America and in the Asia-Pacific region) is used for pain relief and treatment of chronic inflammatory diseases. However, the long-term treatment with this drug can be related with cardiovascular diseases (13). Similarly to diclofenac, we have previously shown that etoricoxib at two different doses ( 6 and $12 \mathrm{mg} / \mathrm{kg} /$ day) was also able to prevent alveolar bone loss in rats with ligature-induced periodontitis (7).

Therefore, finding the proper mechanism that COX-2 inhibition affects periodontal disease is mandatory for the potential clinical use of coxibs. In this way, this study aimed to compare the anti-inflammatory effects of etoricoxib with those of diclofenac in an experimental model of periodontitis in rats.

\section{Material and Methods}

The experimental protocol followed the ARRIVE Guidelines for Animal Research by the National Centre for the Replacement Refinement \& Reduction for Animals $\vec{s}$ in Research.

\section{Animals}

Ninety (90) male Holtzman rats weighting approximately $250 \mathrm{~g}$, were maintained in polypropylene cages (5 animals/ cage) under a 12-h light/dark cycle at a temperature of $22^{\circ} \mathrm{C}$ and received standard laboratory chow and tap water ad libitum. The experimental protocol was approved by the Ethics Committee on Animal Experimentation from the Dental School of Araraquara, State University of São Paulo (UNESP) Araraquara, SP, Brazil (protocol CEEA 18/2003). The sample size was calculated using $G^{*}$ Power 3.1 software with Type I ( $\alpha$ ) and Type II ( $\beta$ ) errors of $5 \%$ and $20 \%$, respectively.

\section{Experimental Protocol}

Anesthesia was applied via intraperitoneal (IP) administration of $90 \mathrm{mg} / \mathrm{kg}$ body weight of ketamine (Francotar, Virbac do Brasil Ind. E Com. Ltda., São Paulo, $\mathrm{SP}$, Brazil) and $10 \mathrm{mg} / \mathrm{kg}$ body weight of xylazine (Virbaxyl 2\% ; Virbac do Brasil Ind. E Com. Ltda., São Paulo, SP, Brazil).

After anesthesia, the animals were subjected to the placement of a cotton ligature (Suturim 3.0; Biodinâmica Química e Farmacêutica Ltda., Ibiporã, PR, Brazil) in the cervical region around both the lower right and left first molars to induce experimental periodontitis (14). In control animals, the ligature was immediately removed (Sham group). Rats were randomly divided into 4 groups, according to the treatments (which started immediately after the ligature placement): 1) Sham + CMC group which received
$0.5 \%$ carboxymethylcellulose sodium (CMC) solution (1 $\mathrm{mL} / \mathrm{kg} /$ day, p.o.), 2) Ligature + CMC (control) group which received $0.5 \%$ CMC solution ( $1 \mathrm{~mL} / \mathrm{kg} /$ day, p.o.), 3) Ligature + diclofenac group which received potassium diclofenac (Brasil S.A., São Paulo, SP, Brazil) suspended in 0.5\% CMC at a dose of $10 \mathrm{mg} / \mathrm{kg} /$ day (p.o.) and 4) Ligature + etoricoxib group which received etoricoxib (Merck \& Co., Inc., Whitehouse Station, NJ, USA) suspended in $0.5 \% \mathrm{CMC}$ at a dose of $10 \mathrm{mg} /$ $\mathrm{kg} /$ day (p.o.). Sham and untreated Ligature groups comprised 10 animals at each experimental time, while treated groups (with either diclofenac or etoricoxib) included 5 animals for each experimental time. All drugs were administrated by gavage as single daily dose. After 7, 14 or 21 days following the start of the pharmacological treatments, animals of each group were euthanized with chloral hydrate ( $25 \mathrm{mg} / \mathrm{kg}$, i.p.). The mandibles were removed for radiographic assessment of alveolar bone loss. Samples of gingiva surrounding the lower first molars were collected for determination of $\mathrm{PGE}_{2}$ contents. Samples containing alveolar bone and periodontal ligament from the lower first molar region were collected from the Sham and untreated Ligature groups (5 animals) group/ time) with an endodontic file \#40, put into Trizolcontaining tubes and immediately frozen at $-80{ }^{\circ} \mathrm{C}$ for further analysis of COX-2 gene expression.

\section{Analysis of COX-2 Gene Expression}

COX-2 gene expression was determined in the alveolar bone and periodontal ligament samples by real-time quantitative polymerase chain reaction (qPCR). Total RNA was extract by the Trizol reagent method, according to the manufacturer protocol (Life Technologies, GIBCO$B R L$, USA). cDNA was synthesized from $1 \mu \mathrm{g}$ of total RNA using Superscript II (Life Technologies) according to the manufacturer's protocol. cDNA samples were stored at -20 ${ }^{\circ} \mathrm{C}$ until processing. Nucleotide sequence of the employed primers has previously been reported, as follows: $\mathrm{COX} 2-3^{\prime}$ AAG GGC CCT GGT GTA GTA GG; 5' ACA TाC СCT TCC TाC GGA AT and HPRT - 3' TGA TTC AAA TCC CTG AAG TGC; 5' AAG CTT GCT GGT GAA AAG GA (15). PCR reactions were performed in a final volume of $12 \mu \mathrm{L}$, containing $3 \mu \mathrm{L}$ of cDNA solution, $3 \mu \mathrm{L}$ of primer and $6 \mu \mathrm{L}$ of Sybr Green. Amplification cycle was proceeded with denaturation for 2 min at $95^{\circ} \mathrm{C}$ ( 40 cycles for COX-2 and HPRT) followed by amplification consisting of a denaturation step at $95{ }^{\circ} \mathrm{C}$ for $15 \mathrm{~s}$, a primer-annealing step at $60{ }^{\circ} \mathrm{C}$ for $60 \mathrm{~s}$, and an extension step at $72{ }^{\circ} \mathrm{C}$ for $15 \mathrm{~min}$. After the last amplification cycle, samples were incubated at $95{ }^{\circ} \mathrm{C}$ for $30 \mathrm{~s}$ of pre-melting and 5 seconds each step of melting (aliquots of PCR reaction products, previously normalized to give equivalent amounts of the HPRT control product in all samples). COX-2 expression relative to the control (Sham group) was calculated by the $2 \Delta \Delta \mathrm{CT}$ method. 


\section{Measurement of Gingival PGE 2 Contents}

The collected gingival tissue samples (5 animals/ group/time) were homogenized with $300 \mu \mathrm{L}$ of $20 \mathrm{mmol} / \mathrm{L}$ phosphate buffered saline solution (PBS, $\mathrm{pH}$ 7.4). The homogenates were then centrifuged ( $15 \mathrm{~min}$ at $10,000 \mathrm{~g}$ ) and $35 \mu \mathrm{L}$ of each supernatant were collected and kept at $-80^{\circ} \mathrm{C}$ until analyzed for their $\mathrm{PGE}_{2}$ concentrations by using an ELISA kit (RED Systems, Inc., Minneapolis, MN, USA) following the manufacturer's instructions.

\section{Radiographic Examination of Bone Loss}

The mandibles from 5 animals/group at each time were removed and subjected to manual cleaning, boiling and subsequent immersion in $2 \mathrm{~N} \mathrm{NaOH}$ solution in order to complete the removal of soft tissue. Standardized digital radiographs of hemimandibles (right and left) were performed by using a computerized imaging system (Computed Dental Radiography for Microsoft Windows, Shick Technologies, Inc., Dialom Dental Products, Long Island City, NY). Electronic sensors were exposed to 65 $\mathrm{KVvp}$ and $10 \mathrm{~mA}$ with exposure time of 12 pulses/ second. Distance between focus and film was standardized at $50 \mathrm{~cm}$, and an aluminum wedge was incorporated in the electronic sensor to provide radiographic density reference. Three measurements were made of each X-ray to identify the extent of bone loss (in $\mathrm{mm}$ ). The images were digitalized and the distance from the alveolar bone crest to the cementoenamel junction of mesial side in the first jaw molars of each rat was measured using the software ImageJ by an investigator familiarized with the software and unaware of the group to which each sample belongs (7).

\section{Statistical Analysis}

All the values are expressed as mean \pm standard error of the mean (SEM). Statistical analysis was performed using the software GraphPad Prism 6 (GraphPad Software Inc. - San Diego, California, USA). The Kolmogorov-Smirnov test was applied to all groups to check data distribution. Because all values were normally distributed, statistical analyses were carried out using one-way analysis of variance (ANOVA) followed by the Sidak's test for multiple comparisons. COX-2 expression differences due to the presence of ligature was analyzed by the Student $t$ test for unpaired data. The correlation between alveolar bone loss and COX-2 expression was analyzed by Pearson's correlation coefficient. Values of $p<0.05$ were considered as statistically significant.

\section{Results}

\section{Clinical Adverse Effects Observation}

No clinically relevant manifestations were observed in the animals treated with either drug. All rats gained weight and none of them showed any visible clinical abnormality or palatal/ lingual mucosa alterations.

\section{COX-2 Gene Expression in Alveolar Bone And Periodontal Ligament}

Figure 1 shows that experimental induction of periodontal disease by ligature led to significant increase of COX-2 expression in the alveolar bone and periodontal ligament samples as analyzed $7(0.7 \pm 0.4$ vs. $4.1 \pm 1.4)$, $14(1.0 \pm 0.3$ vs. $3.7 \pm 0.8)$ or $21(0.5 \pm 0.2$ vs. $6.3 \pm 2.2)$ days after ligature placement $(\mathrm{p}<0.05)$. These values strongly and significantly correlated with the alveolar bone loss measurements $(r=0.9,95 \% \mathrm{Cl} 0.3$ to $1.0 ; p<0.05)$.

\section{Gingival $P G E_{2}$ Contents}

Figure 2 shows that diclofenac treatment led to a significant decrease of gingival $\mathrm{PGE}_{2}$ in contents on days 7 and 14 following ligature placement ( 7 days: $7.3 \pm 1.4$; 14 days: $9.3 \pm 0.9$ vs. untreated Ligature group: $18.6 \pm 4.4$ and $22.0 \pm 3.8$, respectively; $p<0.05$ ). On the other hand, etoricoxib had no effect on gingival $\mathrm{PGE}_{2}$ at either time.

\section{Alveolar Bone Loss}

Figure 3 presents the linear bone loss measurements $(\mathrm{mm})$. Both treatments (etoricoxib and diclofenac) resulted in significant reduction in alveolar bone resorption compared to Ligature group (control) (7 days: Etoricoxib $0.4 \pm 0.0$ and Diclofenac $-0.3 \pm 0.0$ vs. Ligature $-0.7 \pm 0.0 ; 14$ days: $0.7 \pm 0.1$ and $0.6 \pm 0.1$ vs. $1.0 \pm 0.1 ; 21$ days: $0.8 \pm 0.0$ and $0.7 \pm 0.1$ vs. $1.5 \pm 0.1 ; p<0.05$ ). All of these three groups were significantly different compared with the Sham group (7 days: $0.1 \pm 0.0 ; 14$ days: $0.1 \pm 0.0 ; 21$ days: $0.2 \pm 0.0 ; p<0.001$. However, there was no statistical difference between

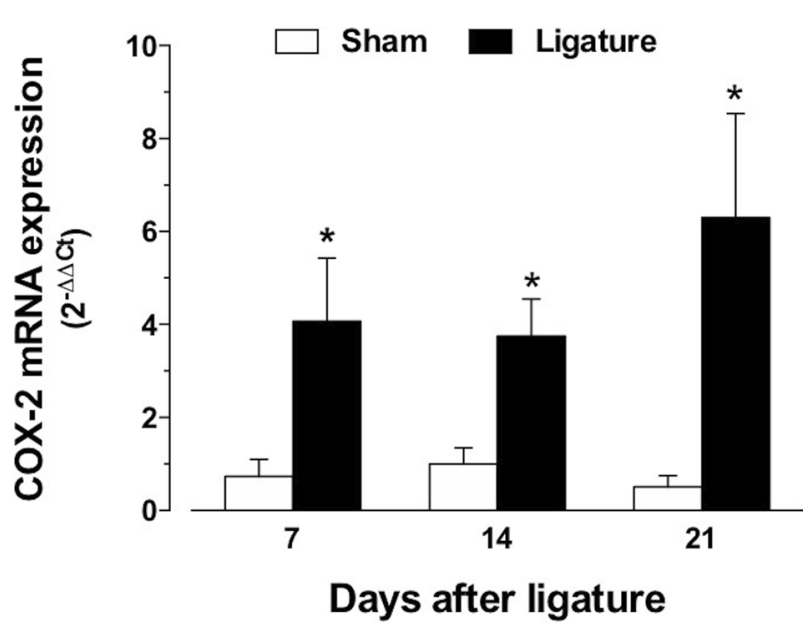

Figure 1. Assessment of COX-2 gene expression in alveolar bone and periodontal ligament tissues from rats with ligature-induced periodontitis as a function of time. ${ }^{*} \mathrm{p}<0.05$ vs. Sham group $(\mathrm{n}=5$ for each group). 
Etoricoxib and Diclofenac groups.

\section{Discussion}

COX-2 expression in alveolar bone and periodontal ligament of the group submitted to experimental periodontitis led us to suggest that this isoform plays a central role during the inflammation, even when the process chronicises. The significant increase of COX-2 agrees with Offenbacher et al. (16), who also demonstrated that alveolar bone loss is related with an intensification of COX-2 expression.

Synthesis of COX-2 during inflammation is responsible for the release of $\mathrm{PGE}_{2}$ which favors periodontal breakdown, as there is vasodilatation, recruitment of inflammatory cells and destruction of collagen and reabsorption of bone $(9,11)$. Although these results suggest that $\mathrm{PGE}_{2}$ is probably derived from $\mathrm{COX}-2$, the role of $\mathrm{COX}-1$ can not be excluded $(9,17,18)$.

While it is recognized that COX-1 is constitutively expressed in most tissues, it is now well known that this enzyme can contribute with $\mathrm{PGE}_{2}$ synthesis during inflammatory processes, differently from the concept that this prostanoid is exclusively derived from COX-2 (17). COX-1 can increase neutrophil migration and induce the loss of the fiber attachment at the periodontal site resulting in development or progression of periodontitis (9). In osteoarthritic patients both COX isoforms are expressed, which indicates that a considerable percentage of $\mathrm{PGE}_{2}$ could come from COX-1 (18).

In our study, only diclofenac caused significant decrease of gingival $\mathrm{PGE}_{2}$ measured 7 and 14 days after ligature placement while etoricoxib-treated animals showed gingival $\mathrm{PGE}_{2}$ contents similar to controls at all the evaluated experimental times. It is interesting to note that in another experimental model of inflammatory disease (rheumatoid disease), etoricoxib was capable of reducing $\mathrm{PGE}_{2}$ on plasma, although less potently than diclofenac $(19,20)$. In addition, an in vitro study (neuronal cells and macrophages) compared a selective COX-1 inhibitor with a selective COX-2 inhibitor and showed inhibition of $\mathrm{PGE}_{2}$ in both situations (17).

In a previous study, diclofenac was shown to reduce both leukocytosis and neutrophilia on the first day after ligature in rats, and leukocytosis on the 11th day (11). However, an in vitro study from patients with primary osteoarthritis of Knorth et al. (18) showed that a coxib (SC-58125) achieved only $60 \%$ of diclofenac efficacy, thus, suggesting that selective COX-2 inhibitors are less efficient than classical NSAIDs in suppressing $\mathrm{PGE}_{2}$ production during inflammatory processes (18). However, it is important to state that the anti-inflammatory actions of coxibs are not only due to their ability to decrease $\mathrm{PGE}_{2}$ production, as these drugs can also block important interleukins (i.e., IL-6) involved in the process of periodontal destruction (21). Authors have found that a selective COX-2 inhibitor can interfere on the levels of PGF2 $\alpha$, which is more able to enhances the levels of IL-6 than of $\mathrm{PGE}_{2}$ (22).

Regarding prevention of bone loss, we have previously demonstrated that etoricoxib (at $6 \mathrm{mg} / \mathrm{kg}$ and $12 \mathrm{mg} / \mathrm{kg}$ ) is effective in the prevention of alveolar bone loss in rats with ligature-induced periodontits (7), and similar results were obtained by Mendes et al. using $10 \mathrm{mg} / \mathrm{kg}$ etoricoxib (23), which is the dose used in the present study.
Figure 3. Effects of treatment with diclofenac or etoricoxib on alveolar bone loss secondary to ligature-induced periodontitis in rats as a function of time. ${ }^{* * * *} \mathrm{p}<0.001$ vs. Sham; $\# \mathrm{p}<0.05$ and \#\#\#p<0.001 vs. the untreated Ligature group ( $\mathrm{n}=5$ for each group). 
In addition to the COX-1 hypothesis, and independently of the lack of effects of etoricoxib on gingival $\mathrm{PGE}_{2}$ contents, treatment with this compound resulted in beneficial effects in terms of progression of periodontal disease and prevention of alveolar bone loss similarly to diclofenac. This probably means that either the drugs have differential bioavailability at the gingiva to inhibit COX-2 and consequently $\mathrm{PGE}_{2}$ production or gingival $\mathrm{PGE}_{2}$ does not parallel its production at deeper sites (mainly alveolar bone and odontoblast) where bone resorption actually takes place.

In agreement with our results, Queiroz-Junior et al. (9) demonstrated that treatment of rats with periodontitis with either a coxib or a non-selective NSAID results in reduced alveolar bone loss. Taking into account the main role of COX-1 in physiological functions, many papers have preferentially focused on COX-2 inhibition by coxibs $(9,11)$. However, even being both classical NSAIDs and coxibs effective for the control of periodontal disease progression in experimental animal models, special caution must be taken if translating these observations into clinics, considering the severe side effects that both groups of drugs present, mainly in terms of gastrointestinal and renal damage caused by classical non-selective NSAIDs and the exacerbation of mortality observed in patients with cardiovascular diseases under long-term treatment with coxibs $(18,19,24)$.

The results of the results clearly show that both etoricoxib and diclofenac reduce alveolar bone loss in rats with ligature-induced periodontitis. Whether these findings can be of clinical application as adjuvant therapy to the classical surgical treatment of patients with periodontitis remains to be carefully studied, considering the limitations of COX inhibition in terms of the deleterious side effects associated.

\section{Resumo}

No presente estudo nós comparamos os efeitos de um inibidor seletivo da COX-2 (etoricoxibe) com um anti-inflamatório não esteroidal não seletivo (AINE) (diclofenaco de potássio) no processo inflamatório e perda óssea alveolar em modelo de periodontite experimental. Noventa ratos Holtzman machos $(250 \mathrm{~g})$ foram randomizados em quatro grupos experimentais: Sham+CMC e Ligadura+CMC (controle) que receberam solução de carboximetilcelulose de sódio (CMC) a 0,5\%; Ligadura+Diclofenaco e Ligadura+Etoricoxibe que receberam diclofenaco de potássio e etoricoxibe, respectivamente, suspensos em CMC 0,5\% (10 mg/kg/dia). 7, 14 e 21 dias após colocação de ligadura bilateral na região cevical dos primeiros molares inferiores, os animais foram submetidos à eutanásia. No fim de cada período, as mandibulas foram coletadas para exame radiográfico de perda óssea alveolar. Em adição, osso alveolar e ligamento periodontal foram coletados para determinar a expressão da enzima COX-2, e o tecido gengival foi coletado para determinar a expressão de $\mathrm{PGE}_{2}$. Animais submetidos à indução da doença periodontal pela ligadura (Grupo Ligadura) apresentaram um aumento significativo da expressão gênica de COX-2 nos dias 7, 14 e $21(p<0,05)$. Todavia, ambos os tratamentos resultaram em uma significativa redução da perda óssea alveolar em comparação ao grupo Ligadura $(p<0,05)$. Esse estudo mostrou que ambos os fármacos foram capazes de reduzir a perda óssea alveolar após indução da doença periodontal.

\section{Acknowledgements}

This work was supported by CAPES and FAPESP. MNM is recipient of a CNPq fellowship.

\section{References}

1. Eke PI, Dye BA, Wei L, Slade GD, Thornton-Evans GO, Borgnakke WS, et al. Update on prevalence of periodontitis in adults in the United States: NHANES 2009 to 2012. J Periodontol 2015;86:611-622.

2. Van Dyke TE, Serhan CN. Resolution of inflammation: a new paradigm for the pathogenesis of periodontal diseases. J Dent Res 2003;82:8290.

3. Baehni PC. Translating science into action-prevention of periodontal disease at patient level. Periodontol 2000 2012;60:162-172.

4. Kotsakis GA, Thai A, Ioannou AL, Demmer RT, Michalowicz BS. Association between low-dose aspirin and periodontal disease: results from the continuous national health and nutrition examination survey (NHANES) 2011-2012. J Clin Periodontol 2015;42:333-341.

5. Pradeep AR, Manjunath SG, Swati PP, Shikha C, Sujatha PB. Gingival crevicular fluid levels of leukotriene B4 in periodontal health and disease. J Periodontol 2007;78:2325-2330.

6. Alani A, Seymour R. Systemic medication and the inflammatory cascade. Periodontol 2000 2014;64:198-210.

7. Holzhausen M, Spolidorio DM, Muscara MN, Hebling J, Spolidorio LC. Protective effects of etoricoxib, a selective inhibitor of cyclooxygenase-2, in experimental periodontitis in rats. J Periodont Res 2005;40:208-211.

8. Pouliot M, Clish CB, Petasis NA, Van Dyke TE, Serhan CN. Lipoxin A(4) analogues inhibit leukocyte recruitment to Porphyromonas gingivalis: a role for cyclooxygenase-2 and lipoxins in periodontal disease. Biochem 2000;39:4761-4768.

9. Queiroz-Junior CM, Pacheco CM, Maltos KL, Caliari MV, Duarte ID, Francischi JN. Role of systemic and local administration of selective inhibitors of cyclo-oxygenase 1 and 2 in an experimental model of periodontal disease in rats. J Periodont Res 2009;44:153-160.

10. Dubois RW, Melmed GY, Henning JM, Bernal M. Risk of Upper Gastrointestinal injury and events in patients treated with cyclooxygenase (COX)-1/COX-2 nonsteroidal antiinflammatory drugs (NSAIDs), COX-2 Selective NSAIDs, and gastroprotective cotherapy: an appraisal of the literature. J Clin Rheumatol 2004;10:178-189.

11. Jagadish R, Mehta DS. Comparative evaluation of the efficacy of the cyclooxygenase pathway inhibitor and nitric oxide synthase inhibitor in the reduction of alveolar bone loss in ligature induced periodontitis in rats: An experimental study. J Ind Soc Periodontol 2014;18:59-64.

12. Zloh M, Perez-Diaz N, Tang L, Patel P, Mackenzie LS. Evidence that diclofenac and celecoxib are thyroid hormone receptor beta antagonists. Life sciences 2016;146:66-72.

13. Riendeau D, Percival MD, Brideau C, Charleson S, Dubé D, Ethier D, et al. Etoricoxib (MK-0663): preclinical profile and comparison with other agents that selectively inhibit cyclooxygenase-2. J Pharmacol Experiment Ther 2001;296:558-566.

14. Holzhausen M, Rossa Junior C, Marcantonio Junior E, Nassar PO, Spolidorio DM, Spolidorio LC. Effect of selective cyclooxygenase-2 inhibition on the development of ligature-induced periodontitis in rats. J Periodontol 2002;73:1030-1036.

15. Ferraz JG, Sharkey KA, Reuter BK, Asfaha S, Tigley AW, Brown ML, et al. Induction of cyclooxygenase 1 and 2 in the rat stomach during endotoxemia: role in resistance to damage. Gastroenterol 1997;113:195-204.

16. Offenbacher $\mathrm{S}$, Heasman PA, Collins JG. Modulation of host $\mathrm{PGE}_{2}$ secretion as a determinant of periodontal disease expression. J Periodontol 1993;64:432-444.

17. Brenneis $C$, Maier TJ, Schmidt R, Hofacker $A$, Zulauf $L$, Jakobsson PJ, et al. Inhibition of prostaglandin E2 synthesis by SC-560 is independent 
of cyclooxygenase 1 inhibition. FASEB 2006;20:1352-1360.

18. Knorth $H$, Dorfmüller $P$, Lebert $R$, Schmidt WE, Wittenberg $R H$, Heukamp $M$, et al. Participation of cyclooxygenase- 1 in prostaglandin E2 release from synovitis tissue in primary osteoarthritis in vitro. Osteoarthritis Cartilage. Osteoart Res Soc 2004;12:658-666.

19. Felden $L$, Walter $C$, Angioni $C$, Schreiber $Y$, von Hentig N, Ferreiros $\mathrm{N}$, et al. Similar maximum systemic but not local cyclooxygenase-2 inhibition by $50 \mathrm{mg}$ lumiracoxib and $90 \mathrm{mg}$ etoricoxib: a randomized controlled trial in healthy subjects. Pharm Res 2014;31:1813-1822.

20. Schwartz JI, Dallob AL, Larson PJ, Laterza OF, Miller J, Royalty J, et al. Comparative inhibitory activity of etoricoxib, celecoxib, and diclofenac on COX-2 versus COX-1 in healthy subjects. J Clin Pharmacol 2008:48:745-754.

21. Tipton DA, Flynn JC, Stein SH, Dabbous M. Cyclooxygenase-2 inhibitors decrease interleukin-1beta-stimulated prostaglandin E2 and IL-6 production by human gingival fibroblasts. J Periodontol 2003;74:1754-
1763.

22. Vardar $\mathrm{S}$, Baylas $\mathrm{H}$, Huseyinov A. Effects of selective cyclooxygenase-2 inhibition on gingival tissue levels of prostaglandin E2 and prostaglandin F2alpha and clinical parameters of chronic periodontitis. J Periodontol 2003;74:57-63.

23. Mendes RT, Sordi R, Olchanheski LR Jr, Machado WM, Stanczyk CP, Assreuy J, et al. Periodontitis increases vascular cyclooxygenase-2: potential effect on vascular tone. J Periodont Res 2014;49:85-92.

24. Lohinai Z, Stachlewitz R, Szekely AD, Feher E, Dezsi L, Szabo C. Evidence for the expression of cyclooxygenase-2 enzyme in periodontitis. Life Sci 2001;70:279-290. 